\title{
ISOLAMENTO DA GLOBULINA MAJORITÁRIA, DIGESTIBILIDADE IN VIVO E IN VITRO DAS PROTEÍNAS DO TREMOÇO-DOCE (Lupinus albus L.), VAR. MULTOLUPA ${ }^{1}$
}

\author{
Valdir Augusto NEVES ${ }^{2 *}$, Sinézio Inácio SILVA Jr. ${ }^{3}$, Maraiza Aparecida da SILVA ${ }^{2}$
}

\begin{abstract}
RESUMO
Os objetivos do trabalho foram isolar, purificar e estudar algumas propriedades da fração globulina majoritária de tremoço-doce, var. Multolupa; assim como avaliar as características de digestibilidade da farinha e frações isoladas. As frações protéicas foram separadas por fracionamento diferencial com uso de diferentes solventes. A globulina majoritária de tremoço-doce foi isolada, purificada por cromatografia em $\mathrm{Q}$-Sepharose, revelando um único pico de proteína. Apresentou um peso molecular de 162,5 $\pm 10,0$ kDa, determinado por cromatografia em Sephacryl S-300, e subunidades entre 20-70 kDa em PAGE-SDS. A solubilidade em função do $\mathrm{pH}$ e concentrações de $\mathrm{NaCl}$ revelaram curva típica dessa fração. A digestibilidade da proteína da farinha e das frações albumina, globulina e glutelina foi avaliada por experimentos in vitro e in vivo e se revelou alta para a fração globulina, seguida pela glutelina, albumina e farinha. A digestibilidade in vivo da fração globulina, tanto aparente quanto verdadeira, não diferiu significativamente daquela determinada para a caseína. Apesar da alta digestibilidade da fração majoritária e frações protéicas, a utilização como única fonte de proteína nas dietas revelou valores baixos de RPLR (razão protéica líquida relativa), indicando ser insuficiente para sustentar o crescimento dos animais, comparativamente à caseína.

Palavras-chave: Lupinus albus, frações protéicas, globulina principal, digestibilidade in vitro e in vivo, ensaio biológico.
\end{abstract}

\section{SUMMARY}

ISOLATION OF MAJOR GLOBULIN, IN VIVO AND IN VITRO DIGESTIBILITY OF PROTEINS FROM SWEET LUPIN (Lupinus albus L.) VAR. MULTOLUPA. The aim of the present work was to isolate, purify and study some properties of the major globulin fraction from sweet lupin, var. Multolupa; as well as to evaluate the digestibility features of flour and isolated fractions. The protein fractions were separated by differential fractionation with different solvents. The lupin major globulin was isolated, purified by $\mathrm{Q}$-Sepharose chromatography when it showed only one protein peak. The major protein presented a molecular weight of $162.5 \pm 10.0 \mathrm{kDa}$, determined on Sephacryl S-300 chromatography; and subunits between 20 to $70 \mathrm{kDa}$ on SDS-PAGE. The protein solubility in relation to pH and $\mathrm{NaCl}$ concentrations showed a typical S-like curve for globulins. The flour and the isolated protein fractions, albumins, globulins and glutelins were evaluated by in vitro and in vivo experiments. The in vitro and in vivo digestibility assays revealed a high digestibility for the globulin, followed by glutelin, albumin and the flour. The globulin in vivo digestibility did not differ significantly from that obtained to casein. Despite the high digestibility encountered for the major protein fraction and protein fractions, the use as the only protein source in the diets revealed low values for RNPR (relative net protein ratio), showing it to be insufficient in terms of sustaining the growth of animals, comparatively to casein.

Keywords: Lupinus albus, protein fractions, major globulin, in vitro and in vivo digestibility, biological assay.

\section{1 - INTRODUÇÃO}

As sementes de leguminosas utilizadas na alimentação contêm cerca de $20 \%$ a $30 \%$ de proteína, exceto a soja e tremoço que apresentam maiores teores [46, 47]. Apesar do alto teor protéico, a qualidade nutricional das proteínas de reserva de leguminosas mostra-se baixa em comparação com fontes protéicas de origem animal. Isso resulta, entre vários fatores, de características estruturais, da digestibilidade e da deficiência de aminoácidos sulfurados das proteínas, assim como da presença de fatores antinutricionais, em especial os inibidores de tripsina e lectinas [3, 4, 14, 19, 23, 25].

\footnotetext{
${ }^{1}$ Recebido para publicação em 30/1/2006. Aceito para publicação em 20/10/2006 (001669)

${ }^{2}$ Departamento de Alimentos e Nutrição,

Faculdade de Ciências Farmacêuticas,

Universidade Paulista Julio de Mesquita Filho (UNESP),

Rodovia Araraquara-Jaú, Km 1, CEP 14801-902, Araraquara (SP),

E-mail:nevesva@fcfar.unesp.br

${ }^{3}$ Centro Universitário de Araraquara (UNIARA),

Araraquara (SP), Brasil

* A quem a correspondência deve ser enviada
}

A fração protéica total das leguminosas é uma mistura complexa de globulinas (40-60\%), albuminas (8-20\%), prolaminas e glutelinas, sendo as duas primeiras os principais componentes [5, 12], em proporções que oscilam entre as espécies, variedades e/ou cultivares [16, 32, 46]. Apesar da maior fração ser constituída por globulinas, apresenta menor qualidade nutricional que as albuminas, por isso, uma maior proporção da última equivale a uma melhora no valor nutricional da proteína da semente $[4,17,37,48]$.

Espécies de leguminosas com alto conteúdo protéico e de fácil adaptação às características de clima e solo têm sido objeto de estudo em diversos países, inclusive no Brasil. Dentre as espécies pesquisadas podemos destacar o tremoço (Lupinus), por constituir-se em uma das mais ricas fontes de proteínas entre as sementes de leguminosas, em que teores variáveis entre 28 e $51 \%$ de proteína tem sido reportado para diferentes variedades [7, 11, 13, 24, 33, 45]. Estudos de caracterização das proteínas das sementes de tremoço demonstram diferenças consideráveis em função da variedade, método de extração e do procedimento físico-químico utilizado [6, 7, 18, 34]. A presença de substân- 
cias antinutricionais e tóxicas tem sido substancialmente reduzida por meio de cruzamentos intervariedades, em especial as variedades "doces". A digestibilidade aparente e verdadeira da semente crua e aquecida de Lupinus albus revelou valores de 72,9 e $79,2 \%$, comparado a $87 \%$ para a caseína [10]. Enquanto a estrutura compacta da fração globulina majoritária de certas espécies, tais como o feijão [9, 23, 29, 37], grão-de-bico [15, 50], lentilha [32] e soja [9, 38,39 ], tem sido associada à digestibilidade reduzida, não há na literatura muitas informações sobre a influência das diferentes frações protéicas do tremoço na digestibilidade da proteína da semente.

Em razão do exposto, o presente trabalho teve como objetivos: isolar, purificar, estudar as características de solubilidade da globulina majoritária; e avaliar, por métodos "in vitro" e "in vivo", a digestibilidade da farinha descorticada, das frações albumina, globulina total, globulina majoritária e glutelina, assim como sua influência na qualidade nutricional da semente de Lupinus albus L., var. Multolupa.

\section{2 - MATERIAL E MÉTODOS}

\section{1 - Material}

Sementes de tremoço-doce (Lupinus albus L.) var. Multolupa, provenientes da Estação Experimental da Embrapa de Passo Fundo-RS, Brasil, foram escolhidas e limpas de sujidades, maceradas em água $\left(18 \mathrm{~h} / 4{ }^{\circ} \mathrm{C}\right.$ ), descascadas manualmente e secas à temperatura ambiente. Na seqüência, procedeu-se à moagem em moinho de bolas, tamisação (60 mesh) e desengorduramento com hexano a frio, obtendo-se a farinha de tremoço desengordurada. Todos os reagentes químicos utilizados nas análises foram de grau analítico (p.a.).

\section{2 - Métodos}

\subsection{1 - Isolamento das frações protéicas, determinação de nitrogênio e proteínas}

A extração e isolamento das frações protéicas foram realizados de acordo com o procedimento descrito por SATHE \& SALUNKHE [43]. O nitrogênio total foi determinado pelo método de KjeldhaL [2] e o teor de proteína estimado utilizando-se o fator de conversão de 6,25. A proteína foi também determinada pelo método de LOWRY et al. [27], utilizando-se albumina de soro bovino como padrão. A medida de absorvância a $280 \mathrm{~nm}$ foi utilizada para acompanhamento da proteína nas colunas cromatográficas.

\subsection{2 - Isolamento e purificação da globulina principal}

Alíquotas de $10 \mathrm{~g}$ da farinha desengordurada foram dispersas em água destilada-desionisada, na proporção $1: 10$ p/v, submetidas à agitação mecânica por $4 \mathrm{~h}$ a $4{ }^{\circ} \mathrm{C}$ e, a seguir, à centrifugação a 15000 g. $\mathrm{O}$ sobrenadante foi descartado e o resíduo, disperso em tampão Tris- $\mathrm{HCl} 0,1 \mathrm{M}, \mathrm{pH} 8,0$, contendo $10 \%$ de $\mathrm{NaCl}, 0,05 \%$ de $\mathrm{NaN}_{3}$ e $0,1 \mathrm{mM}$ de EDTA. A dispersão, após agitação mecânica a $4{ }^{\circ} \mathrm{C}$, foi centrifugada a 30000 g, o sobrenadante, recolhido e o resíduo, descartado. Ao sobrenadante foi adicionado $\left(\mathrm{NH}_{4}\right) \mathrm{SO}_{4}$, até $80 \%$ de saturação, sob agitação mecânica por 3 h e centrifugada a 30000 g. O sobrenadante foi descartado e o precipitado, contendo a globulina total, dissolvido em tampão fosfato de potássio 0,15 M, pH 7,0, seguido de cromatografia em coluna de Sephadex G-25 (50 x 1,7 cm), previamente equilibrada com o mesmo tampão, para remoção de compostos de baixo peso molecular. O eluato da Sephadex G-25 foi aplicado em coluna de troca iônica de $\mathrm{Q}$-Sepharose $(30 \mathrm{x}$ $1,5 \mathrm{~cm}$ ), previamente equilibrada com tampão Tris- $\mathrm{HCl}$ $0,05 \mathrm{M}, \mathrm{pH} 7,5$, para separação da globulina majoritária. Após a adsorção, a coluna foi lavada com o mesmo tampão e, na seqüência, a globulina foi eluída em gradiente linear de $\mathrm{NaCl}$ de 0-1,0 M e coletados $5 \mathrm{~mL} /$ tubo. A proteína foi acompanhada por medida da absorvância em $280 \mathrm{~nm}$. A fração correspondente à globulina majoritária foi coletada, liofilizada e utilizada para todos os ensaios.

\subsubsection{1 - Estimativa de peso molecular da globulina majoritária}

A estimativa do peso molecular foi realizada por cromatografia de filtração em gel, de acordo com o procedimento descrito por WHITAKER [51]. Uma coluna de Sephacryl S-300 HR (90 x 1,7 cm), previamente equilibrada com tampão fosfato de potássio $20 \mathrm{mM}, \mathrm{pH} 7,5$, contendo $0,5 \mathrm{M}$ de $\mathrm{NaCl}$ e $0.05 \%$ de $\mathrm{NaN}_{3}$, foi utilizada para a determinação. A proteína, após passagem em coluna de Sepharose CL-CB (100 x 1,8 cm) (tubo pico), foi aplicada na coluna de Sephacryl S-300 HR (90 x 1,7 cm) e, em seguida, foi eluída com o mesmo tampão. Para a elaboração da curva de calibração da coluna, foi utilizado mistura de proteínas de pesos moleculares conhecidos, a saber: citocromo $\mathrm{C}$ de coração de cavalo (12,4 kDa), soralbumina bovina (67 kDa), lactato desidrogenase (130 kDa), miosina (205 kDa), ferritina (480 kDa) e tireoglobulina (680 $\mathrm{kDa})$. O volume de exclusão da coluna foi determinado por meio da eluição de dextrana azul 2000. A eluição da globulina e das proteínas foi acompanhada por medida de absorvância em $280 \mathrm{~nm}$, à exceção do citocromo $\mathrm{C}$, realizado em $550 \mathrm{~nm}$.

\subsubsection{2 - Eletroforese em gel de poliacrilamida}

A determinação de número e peso molecular de subunidades foi obtida em sistema descontínuo de $\mathrm{pH}$, na concentração de acrilamida de $12,5 \%$ e utilizando-se o procedimento descrito por LAEMLLI [26]. As seguintes proteínas com pesos moleculares conhecidos foram utilizadas como padrão: fosforilase b (94 kDa), albumina de soro bovino (67 kDa), ovalbumina (45 kDa), anidrase carbônica (30 kDa), inibidor de tripsina de soja (21,5 kDa) e citocromo C de coração de cavalo $(12,4 \mathrm{kDa})$. 


\subsubsection{3 - Ensaios de solubilidade da globulina majoritária}

Efeito do pH: Alíquotas da globulina nativa isolada foram dispersas em água destilada, com o pH da dispersão ajustado na faixa de pH 2,0 a 12,0 com solução de $\mathrm{HCl}$ ou $\mathrm{NaOH} \mathrm{0,1} \mathrm{N,} \mathrm{e,} \mathrm{a} \mathrm{seguir,} \mathrm{agitadas} \mathrm{mecanicamente} \mathrm{por}$ 1 h. A dispersão foi centrifugada a 30000 g, seguida da determinação da concentração de proteína solubilizada pelo método de LOWRY et al.[27]. Para verificar o efeito do pH na solubilidade da globulina majoritária desnaturada, solução contendo $10 \mathrm{mg}$ de proteína/mL foi autoclavada a $121^{\circ} \mathrm{C} / 15$ min e liofilizada. Deste material, foram tomadas alíquotas em triplicata para os ensaios de solubilidade, conforme descrito para a proteína nativa.

Efeito do NaCl: Para avaliar os efeitos "salting in" e "salting out", alíquotas da globulina principal isolada-purificada, foram dispersas em água destilada, com posterior adição de concentrações crescentes de $\mathrm{NaCl}$. As dispersões, submetidas à agitação mecânica por $1 \mathrm{~h}$, foram centrifugadas a 30000 g e seguidas de determinação de proteína pelo método de LOWRY et al.[27].

Efeitos combinados do pH e NaCl: Foi utilizado o mesmo procedimento descrito acima para o $\mathrm{pH}$, com adição de $\mathrm{NaCl}$ à concentração molar entre 0 e 1,0 M, seguido de agitação mecânica, correção de pH e centrifugação. A proteína solubilizada foi determinada pelo método de LOWRY et al.[27].

\subsection{3 - Digestibilidade in vitro}

A digestibilidade in vitro foi determinada de acordo com o procedimento descrito por AKESON \& STHAMAN [01]. A farinha e frações protéicas isoladas foram hidrolisadas pelo uso de solução de pepsina (SIGMA P-7012), por três horas, procedimento seguido de ajuste de $\mathrm{pH}$, adição de solução de pancreatina (SIGMA P-1750) e banho a $37{ }^{\circ} \mathrm{C}$ por $24 \mathrm{~h}$. A reação foi interrompida pela adição de ácido tricloroacético (TCA) $10 \%$. A percentagem de hidrólise foi determinada pela medida dos novos aminoácidos livres gerados, quantificando-se o número de grupamentos amino-livres no sobrenadante, pela reação com reagente TNBS, conforme descrito por FIELDS [21] e modificado por SPADARO et al. [49]. A digestibilidade foi avaliada após cálculo do grau de hidrólise, tomando-se a caseína (SIGMA C-8654) como padrão (100\%).

\subsection{4 - Ensaio biológico}

Foram utilizados ratos machos, albinos, Wistar, recémdesmamados, entre 21 e 28 dias, provenientes do Biotério Central da UNESP, Campus de Botucatu, divididos em grupos de seis animais cada e mantidos em gaiolas metabólicas individuais, em ambiente com temperatura $\left(24 \pm 1{ }^{\circ} \mathrm{C}\right) \mathrm{e}$ umidade controladas e ciclo de luz de $12 \mathrm{~h}$. Cada experimento durou 10 dias e, após adaptação de dois dias com dieta comercial, os grupos experimentais foram alimentados com dietas elaboradas segundo recomendação do American
Institute of Nutrition, como descrito por REEVES et al. [36], exceto pelo teor de proteína que foi de $10 \%$, provenientes da farinha de tremoço, de suas frações protéicas isoladas e da caseína (Sigma C-7078), adotada na elaboração da dieta controle. Um grupo utilizou dieta aprotéica, para determinação do nitrogênio fecal endógeno, para o cálculo de Razão Protéica Líquida e Digestibilidade Verdadeira. Água e dietas foram oferecidas ad libitum. Os controles de ganho de peso e ingestão feitos a cada dois dias e a coleta das fezes entre o $5^{\circ}$ e $9^{\circ}$ dia de experimento foram utilizados nos cálculos de digestibilidade e Razão Protéica Líquida (RPL).

\subsubsection{1 - Avaliação de nitrogênio fecal e urinário}

As fezes de cada animal dos grupos experimentais foram recolhidas entre o $5^{\circ}$ e $9^{\circ}$ dia de experimento, secas em estufa com circulação de $\operatorname{ar}\left(105^{\circ} \mathrm{C}\right)$ até peso constante, pesadas, pulverizadas, misturadas e homogeneizadas para cada grupo experimental e tiveram o teor de nitrogênio quantificado pelo método de Kjeldhal [2].

Os ensaios foram realizados para cada grupo conforme descrito por McDONOUGH et al. [30], EVANS \& WITTY [20] e PELLET \& YOUNG [35] e calculados de acordo com as fórmulas dadas abaixo:

Digestibilidade aparente: $\mathrm{Da}=\frac{\mathrm{Ni}-\mathrm{Nf}}{\mathrm{Ni}}$

Digestibilidade verdadeira: $\mathrm{Dv}=\frac{\mathrm{Ni}-(\mathrm{Nf}-\mathrm{Nfe})}{\mathrm{Ni}}$ onde $\mathrm{Ni}=$ nitrogênio ingerido, $\mathrm{Nf}=$ nitrogênio fecal, $\mathrm{Nfe}=$ nitrogênio fecal endógeno (calculado a partir dos resultados do grupo com dieta aprotéica em ensaio de nove dias)

Razão Protéica Líquida: $\mathrm{RPL}=$ (ganho de peso $(\mathrm{g})+$ perda média de peso do grupo com dieta aprotéica)/proteína ingerida

Razão Protéica Líquida Relativa:

$$
\mathrm{RPLR}=\frac{\mathrm{RPL} \text { da proteína teste } \times 100}{\mathrm{RPL} \text { proteína padrão (caseína) }}
$$

\subsection{5 - Análise estatística}

Os resultados foram analisados estatisticamente por análise de variância.

\section{3 - RESULTADOS E DISCUSSÃO}

A farinha de tremoço descorticada, proveniente de avaliações realizadas em triplicata, apresentou a seguinte composição química: $12,45 \%$ umidade, 45,94\% de proteínas, 1,76\% lipídeos e 3,52\% de cinzas [33]. Estudo comparativo de 100 amostras de sementes de tremoço de diferentes variedades e procedentes de 12 diferentes países mostrou variações de 30 a $50 \%$ de proteína total; contendo $60 \%$ das amostras de 32 a $38 \%$ de proteína, enquanto $28 \%$ apresentavam teores entre 38-44\% de proteína [7,44]. 
O fracionamento solubilizou aproximadamente $91 \%$ da proteína total da farinha ( $\left.\% \mathrm{~N}_{2} \times 6,25\right)$, sendo $43,42 \%$ de globulinas, $10,77 \%$ de albuminas, $0,49 \%$ de prolaminas e $16,29 \%$ de glutelinas [33]. OOMAH \& BUSHUK [34] encontraram diferentes teores dessas frações em L. angustifolius e L. albus, com variação para diferentes cultivares das espécies. Na cromatografia e eletroforese, a fração albumina do tremoço var. Multolupa mostrou ser composta de uma mistura heterogênea de proteínas, enquanto a globulina total mostrou ser constituída de uma fração majoritária e duas componentes minoritárias [33].

A Figura 1 mostra a separação da globulina majoritária na coluna de $\mathrm{Q}$-Sepharose em que se observa a presença de dois picos, sendo o primeiro correspondente à globulina majoritária. As globulinas de tremoço receberam a designação de $\gamma, \beta$ e $\alpha$-conglutina, descritas por BLAGROVE \& GILLESPIE [07] com base no aumento de sua mobilidade anódica na eletroforese em acetato de celulose, no entanto, CERLETTI et al. [11] observaram que tais proteínas eram eluídas na mesma seqüência na cromatografia de trocaiônica, ou seja: $\gamma$, $\beta$ e $\alpha$. MELO et al. [31] não encontraram a fração $\gamma$, e as outras eluiram em 0,3 M e 0,4 M de $\mathrm{NaCl}$, respectivamente; e o mesmo foi observado na coluna de Q-Sepharose para a variedade Multolupa.

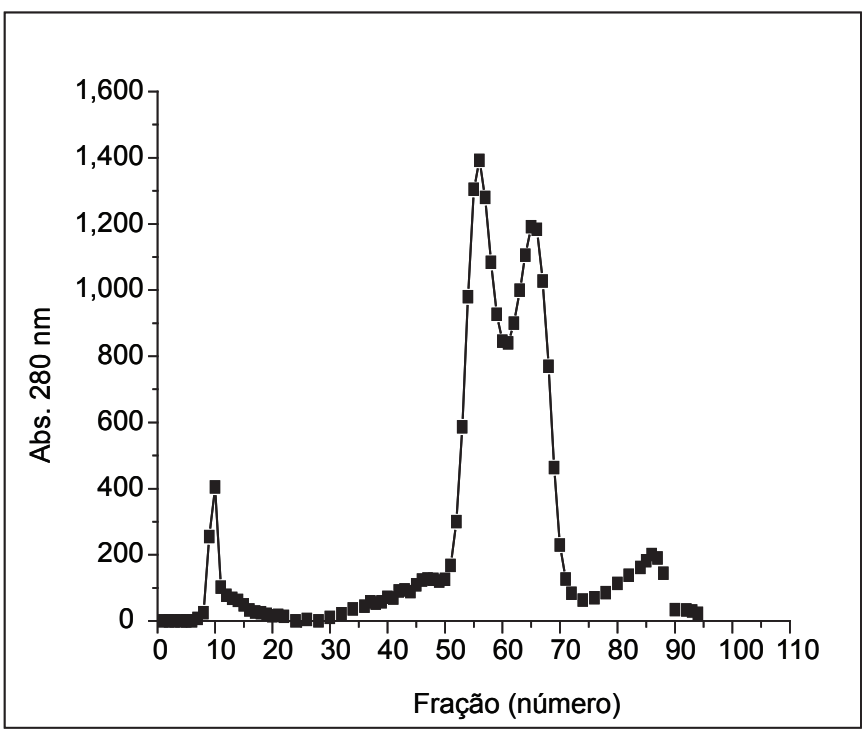

FIGURA 1 - Cromatografia da globulina total de tremoço, var. Multolupa; em coluna de troca iônica de Q-Sepharose (30 X $1,5 \mathrm{~cm})$.

A recromatografia em coluna de $\mathrm{Q}$-sepharose mostrou um único pico (resultados não mostrados). Por outro lado, a reunião dos tubos picos dessa recromatografia em $\mathrm{Q}$-sepharose, seguida de aplicação em coluna de filtração em gel de Sepharose CL-6B ( $100 \times 2,5 \mathrm{~cm}$ ), produziu também um único pico de proteína, correspondente à globulina majoritária do tremoço; conforme mostra a Figura 2. Dentre as várias tentativas de purificação realizadas, a melhor seqüência de etapas, que acabou prevalecendo como procedimento de isolamento-purificação da globulina majoritária do tremoço, foi a aplicação do eluato de Sephadex G-25 na coluna de
Sepharose CL-6B ( $100 \times 2,5 \mathrm{~cm})$. Esse procedimento apresentou uma distribuição sempre uniforme caracterizada por pico de proteína entre as frações 70 e 100 . O peso molecular obtido para a globulina majoritária de tremoço doce, em coluna de Sephacryl S-300 HR (90 x 1,7 cm) correspondeu à fração do tubo 42 (Figura 3), sendo estimado em 162,5 $\pm 10,0 \mathrm{kDa}$. A Figura 4 mostra as eletroforeses em gel de poliacrilamida da globulina majoritária após passagem em Sephadex G-25 e em Sephacryl S-300-HR (90 x 1,7 cm), respectivamente, na qual podemos notar a presença de uma única banda de proteína, equivalente à $\beta$-conglutina, como observado por CERLETTI et al. [11] e MELO et al. [31]. À semelhança do observado pelos autores, a fração $\gamma$ não foi detectada na variedade Multolupa. A observação da Figura 5 permite afirmar que a proteína é composta de subunidades na faixa de 20-70 kDa e que não há pontes dissulfeto na molécula. Esses resultados confirmam aqueles relatados por MELO et al. [31] e BLAGROVE \& GILLESPIE [7].

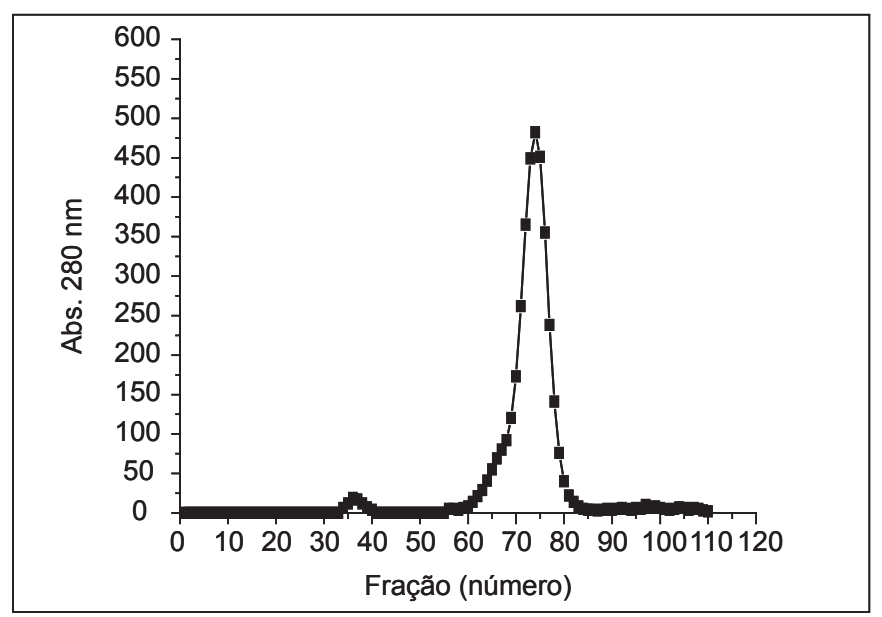

FIGURA 2 - Cromatografia fração globulina majoritária de tremoço, var. Multolupa; em coluna de Sepharose CL-6B (100 x 2,5 cm), após passagem em coluna de $\mathrm{Q}$-Sepharose $(30 \times 1,5 \mathrm{~cm})$.

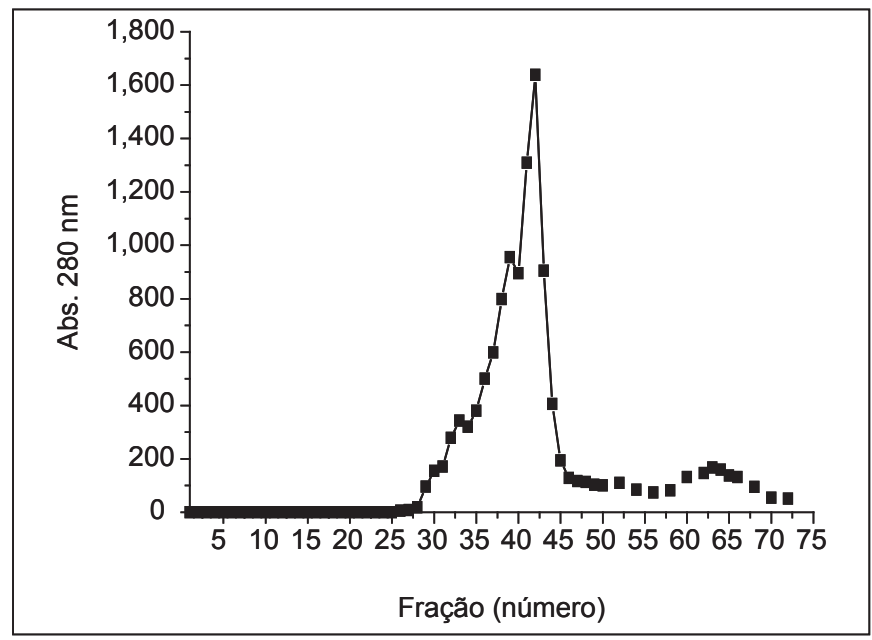

FIGURA 3 - Cromatografia fração globulina majoritária de tremoço, var. Multolupa; em coluna de Sephacryl S-300 HR $(90$ x 1,7 cm), após passagem em coluna de Sephadex G-25. 


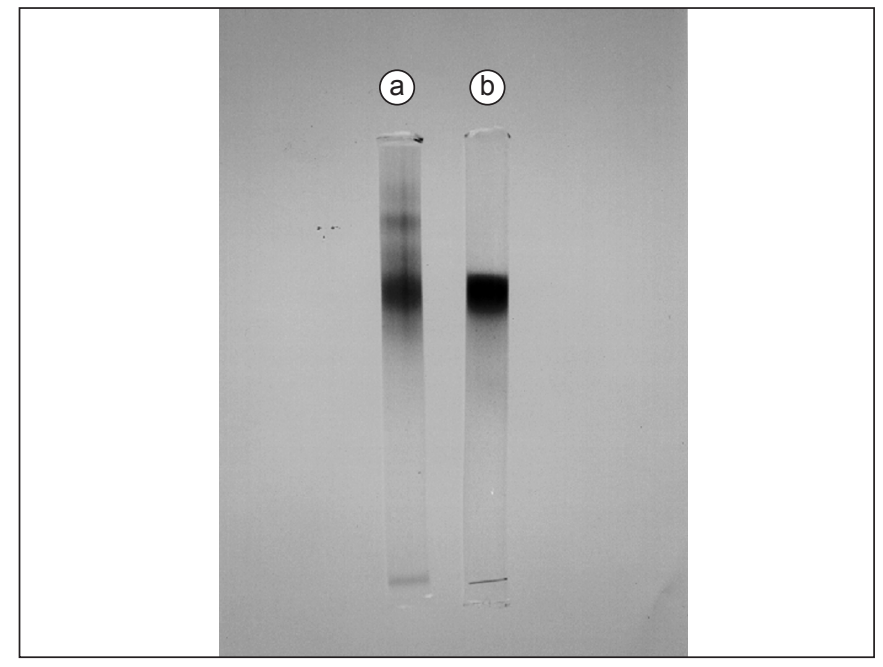

FIGURA 4 - Eletroforese em gel de poliacrilamida a 7\% da globulina majoritária de tremoço eluída em coluna de sephadex g-25 (a) e do tubo pico no cromatograma em coluna de sephacryl s-300 hr $(90 \times 1,7 \mathrm{~cm})(\mathrm{b})$.

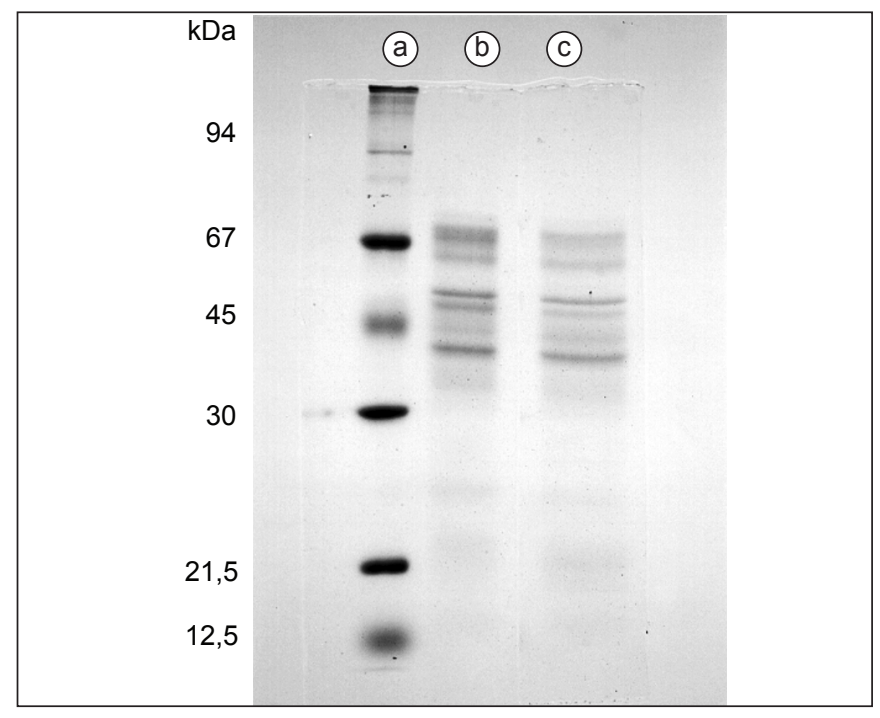

FIGURA 5 - Eletroforese em gel de proliacrilamida dodecilsulfato de sódio da globulina majoritária do tremoço pós eluição na coluna de Sephacryl S-300 HR (90 x 1,7 cm). a) Padrões de peso molecular. b) sem 2-mercaptoetanol; e c) com 2-mercaptoetanol.

A Figura 6 mostra o efeito de $\mathrm{NaCl}$ na solubilidade da globulina majoritária, iniciando-se com a dissolução em 0,05 M do sal e atingindo um máxima a partir de 0,5 M. Os perfis de solubilidade da globulina do tremoço em diferentes valores de $\mathrm{pH}$, em água desionizada e em soluções de $\mathrm{NaCl}$, registrados na Figura 7 , demonstram que o comportamento da proteína na ausência de sal é típico das globulinas de leguminosas, com um $\mathrm{pH}$ mínimo de solubilidade entre pHs 4,5 a 5,0 (pH isoelétrico) [08] . Essas características foram significativamente alteradas quando a proteína foi dissolvida em soluções de $\mathrm{NaCl}$, com elevada solubilidade na região de $\mathrm{pH} 4,5$ a 12,0, inclusive no $\mathrm{pH}$ isoelétrico.

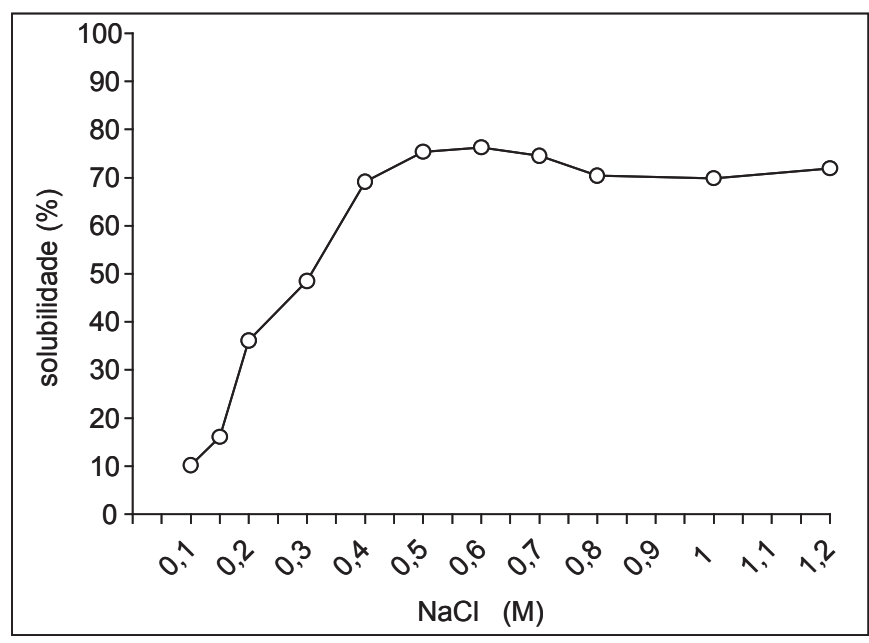

FIGURA 6 - Efeito da concentração de $\mathrm{NaCl}(\mathrm{M})$ na solubilidade da globulina majoritária isolada de tremoço, var. Multolupa.

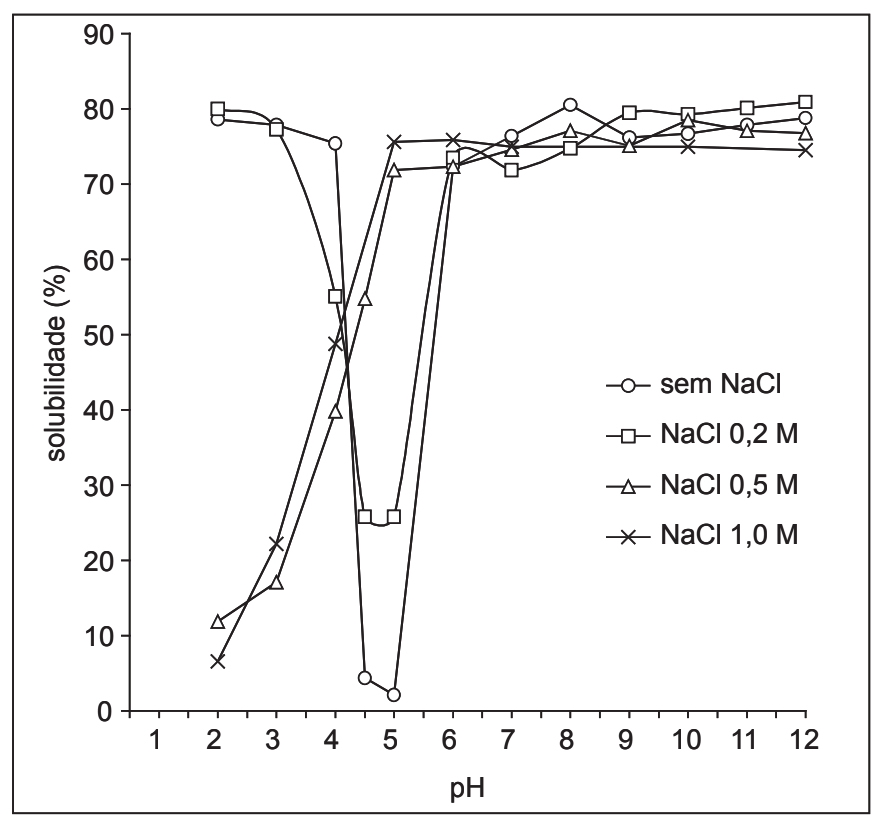

FIGURA 7 - Efeito do $\mathrm{pH}$ e $\mathrm{pH}$ x concentração de $\mathrm{NaCl}$ na solubilidade da fração globulina majoritária de tremoço, var. Multolupa.

\section{1 - Digestibilidade in vitro e in vivo da farinha e das frações protéicas.}

Os valores de digestibilidade in vivo e in vitro da farinha e das frações protéicas autoclavadas, albumina, globulina e glutelina estão na Tabela 1. Embora a digestibilidade in vitro represente tentativa de simular a digestão in vivo, pode-se observar maior aproximação dos valores da digestibilidade aparente, tanto na farinha quanto nas frações protéicas. Entre essas, as globulinas majoritária e total apresentaram maiores valores de digestibilidade in vitro, seguidas pela glutelina; ao passo que a albumina e a farinha exibiram maior resistência à hidrólise seqüencial in vitro pela pepsina-pancreatina, assim como in vivo pelas proteases digestivas do 
TABELA 1 - Ensaio biológico e digestibilidade in vitro da farinha e frações protéicas do tremoço-doce ${ }^{1}$.

\begin{tabular}{|c|c|c|c|c|c|}
\hline $\begin{array}{l}\text { Fonte protéica } \\
\text { (tremoço doce) }\end{array}$ & $\mathrm{RPL}^{2}$ & $\operatorname{RPLR}^{3}(\%)$ & $\begin{array}{c}\text { Digestibilidade } \\
\text { aparente }^{4}\end{array}$ & $\begin{array}{c}\text { Digestibilidade } \\
\text { verdadeira }^{4}\end{array}$ & $\begin{array}{c}\text { Digestibilidade } \\
\text { in vitro }\end{array}$ \\
\hline Caseína (controle) & $5,65^{a} \pm 0,37$ & $100^{a}$ & $90,62^{a} \pm 0,82$ & $97,51^{a} \pm 0,88$ & $93,82^{a} \pm 1,50$ \\
\hline Farinha & $2,44^{b c} \pm 0,22$ & $43,27^{b} \pm 3,99$ & $79,25^{c} \pm 0,00$ & $86,24^{d} \pm 0,00$ & $68,71^{\mathrm{c}} \pm 9,43$ \\
\hline globulina total & $1,77^{c} \pm 0,78$ & $31,18^{c} \pm 14,01$ & $91,29^{a} \pm 1,21$ & $98,20^{\mathrm{a}} \pm 0,69$ & $82,98^{a b} \pm 6,02$ \\
\hline globulina majoritária & nd & nd & nd & nd & $96,69 \pm 2,34$ \\
\hline Albumina & $2,31^{b c} \pm 0,14$ & $40,97^{b c} \pm 2,42$ & $84,27^{b} \pm 0,38$ & $90,32^{\mathrm{c}} \pm 1,16$ & $69,67^{\mathrm{bc}} \pm 1,10$ \\
\hline Glutelina & $2,90^{\mathrm{b}} \pm 0,22$ & $51,32^{b} \pm 3,93$ & $85,28^{b} \pm 0,50$ & $92,52^{\mathrm{b}} \pm 0,54$ & $78,42^{\mathrm{bc}} \pm 1,35$ \\
\hline
\end{tabular}

${ }^{1}$ Aquecidas a $121{ }^{\circ} \mathrm{C} / 15 \mathrm{~min}$, relação 1:5 (m/v); ${ }^{2}$ Razão Protéica Líquida; ${ }^{3}$ Razão Protéica Líquida Relativa (padrão caseína = 100); ${ }^{2,3}$ Período experimental = 10 dias. Dietas formuladas segundo AIN-93 ${ }^{36,}$ A partir do "pool" de fezes dos seis ratos do grupo; Para um mesmo ensaio, valores com letras sobrescritas iguais não apresentam diferença estatística significativa ( $\mathrm{p}<0,05$ ). nd-:não determinada.

rato. Nos ensaios in vivo, a digestibilidade, tanto aparente quanto verdadeira, da fração globulina total não diferiu significativamente daquela determinada para a caseína. Os valores de digestibilidade in vitro da globulina total e da majoritária sugerem que o alto valor da última determina a digestibilidade verdadeira da primeira. A evidência de que as proteínas isoladas apresentaram valores de digestibilidade superiores aos da farinha sugere, também, que outros componentes naturais da semente podem interagir com as proteínas ou com as enzimas digestivas, com reflexos negativos na hidrólise, em especial na fração albumina, pois essa reúne os inibidores de proteases da semente muitas vezes estáveis ao tratamento térmico [19, 22].

MARLETTA et al. [28] verificaram uma alta correlação entre as digestibilidades in vivo e in vitro das proteínas de seis diferentes variedades de feijão com as características de cor da casca. Resultados semelhantes de digestibilidade in vitro da farinha e do concentrado protéico de tremoço foram encontrados por SATHE et al. [44], assim como digestibilidade in vivo da globulina de feijão-comum, variedade Carioca, encontrados por MARQUEZ \& LAJOLO [29] e por COELHO \& SGARBIERI [14] no cultivar IAC-Carioca 80 SH.

CARBONARO et al. [08], em estudos envolvendo as proteínas totais de feijão, grão-de-bico e lentilha, sugerem que a reação de agregação mediada pelos resíduos básicos das globulinas de leguminosas poderia ser uma das razões da reduzida digestibilidade observada após aquecimento. Em outro estudo, CARBONARO et al. [09] apontam que características conformacionais inerentes às globulinas majoritárias, 7S do feijão comum e 11S do feijão fava, poderiam representar importantes fatores na redução da hidrólise, quando da passagem pelo trato gastrointestinal. Os autores observaram, para as proteínas cruas de feijão comum, digestibilidade in vivo de $72,4 \%$, não sendo afetadas pelo aquecimento, por outro lado, a proteína de feijão fava experimentou redução de 86,5 para $60,6 \%$ após aquecimento $\left(120{ }^{\circ} \mathrm{C} / 20 \mathrm{~min}\right)$, indicando a formação de componentes não absorvíveis. A fração globulina de ambas as espécies apresentaram digestibilidade próximas, no entanto, inferiores àquelas do tremoço (var. Multolupa) observadas neste trabalho.

O aquecimento $\left(121^{\circ} \mathrm{C} / 15 \mathrm{~min}\right)$ das frações globulinas de tremoço, total e majoritária, não pareceu afetar a digestibilidade protéica in vivo e in vitro, diferente do observado por CARBONARO et al. [09]. Num estudo com farinha e frações protéicas de grão-de-bico, TAVANO [50] verificou que o aquecimento pouco afetou os valores de digestibilidade da farinha, porém elevou os da fração globulina total tanto in vitro quanto in vivo. RUBIO et al. [38] observaram que as globulinas isoladas de feijão fava ( $V . f a b a)$, tremoço ( $L$. angustifolius) e soja (G. max), quando administradas na forma de suspensão aquosa em ratos por gavagem, apresentavam valores de digestibilidade in vivo de 96,5, 92,4 e $99,9 \%$, respectivamente. Por outro lado, se incorporadas a dietas sólidas havia redução da digestibilidade para 84,4; 86,9 e $80,1 \%$. Segundo os autores, esses resultados indicam que as globulinas isoladas de leguminosas seriam altamente digeríveis no intestino delgado, sendo os valores menores obtidos quando da utilização de farinha integral na dieta, devido a outros componentes naturais presentes, tais como os fatores antinutricionais, taninos e inibidores de proteases.

Apesar da digestibilidade relativamente próxima à caseína observada para as frações protéicas do tremoço (var. Multolupa), a inclusão da farinha e frações como única fonte protéica nas dietas dos ratos não foram suficientes para sustentar o seu crescimento (RPRL) em patamares semelhantes ao observado para a caseína (Tabela 1 ). Sabese que a digestibilidade em si não é o único parâmetro de medida do aproveitamento das proteínas pelo organismo. Nesse sentido, estudos recentes com proteínas purificadas de tremoço, feijão fava, soja e grão-de-bico sugerem que a razão principal do baixo valor nutricional dessas farinhas de leguminosas, além da proporção de aminoácidos de suas proteínas, poderia estar relacionado à estrutura química de suas globulinas e aos efeitos adversos destas e/ou de seus produtos de digestão sobre o crescimento e metabolismo de nitrogênio mais do que à presença de fatores antinutricionais [38, 39, 40, 41, 50].

Recentemente, RUBIO \& SEIQUER [42], utilizando proteínas purificadas de grão-de-bico (11S e 7S), globulinas de feijão fava e de tremoço, verificaram alta digestibilidade in vitro utilizando-se de pepsina-pancreatina, em relação à caseína. Na simulação do processo de absorção, usando um sistema denominado de Caco-2 de cultura de células, os autores sugeriram que os aminoácidos das proteínas de leguminosas são provavelmente absorvidos a velocidades diferentes daqueles de outras proteínas de origem animal, tais como a caseína. Isso já havia sido observado em tra- 
balhos anteriores em que a digestibilidade ideal aparente, em ratos, para a farinha de tremoço foi igual ou mesmo superior à observada para lactalbumina [39]. Nesse mesmo experimento, os autores observaram uma alta excreção de nitrogênio urinário nos ratos alimentados com dietas contendo farinha de tremoço e globulina isolada de tremoço, quando comparado com àquelas contendo lactalbumina e globulina isolada de soja. Foram também detectados maiores níveis plasmáticos de uréia e de triglicérides nos ratos alimentados com a farinha, globulinas de tremoço e globulinas de soja, em relação ao controle com lactalbumina. Segundo os autores, o menor valor nutricional da farinha de tremoço pode estar relacionado mais à estrutura química da globulina e seus efeitos adversos sobre o crescimento e metabolismo de nitrogênio do que à presença de algum fator antinutricional conhecido.

Apesar do envolvimento de outros componentes da farinha não estarem descartados como possíveis responsáveis pelo menor valor nutricional em relação à caseína, os baixos valores de aproveitamento das frações isoladas poderiam estar relacionados a questões de assimilação dos aminoácidos, considerando-se que a digestibilidade verdadeira dessas frações encontram-se próximas àquela da caseína e que, como apontado por muitos estudos, parte da explicação para a biodisponibilidade de uma proteína estaria relacionada a algumas de suas propriedades estruturais, seu conteúdo e seqüência de aminoácidos, o que faz com que mesmo proteínas com certa homologia, como é o caso das globulinas de leguminosas, possam experimentar comportamentos distintos.

\section{4 - CONCLUSÕES}

A fração globulina majoritária de tremoço-doce apresenta peso molecular de $162,5 \pm 10,0 \mathrm{kDa}$, composta de várias subunidades na faixa de 20 - $70 \mathrm{kDa}$ e com características de solubilidade típicas de proteínas de reserva de leguminosas. Os valores de digestibilidade in vitro e in vivo das frações protéicas indicam que a globulina total é mais bem digerida, seguida da fração glutelina, albumina e a farinha. Os valores de digestibilidade in vitro da globulina majoritária sugerem uma influência determinante na digestibilidade verdadeira da globulina total. Nos ensaios in vivo, a digestibilidade, tanto aparente quanto verdadeira, da fração globulina total não diferiu significativamente daquela determinada para a caseína. Os valores observados de digestibilidade in vitro e in vivo das frações isoladas em relação à farinha indicam a possível presença de elementos com influência no processo de digestão. Embora a digestibilidade das frações protéicas encontrarem-se próximos à da caseína, a inclusão da farinha e frações como única fonte protéica na dieta dos ratos não foi suficiente para garantir seu crescimento (RPRL) nos níveis observados para a proteína padrão.

\section{5 - REFERÊNCIAS BIBLIOGRÁFICAS}

[1] AKESON, W. R.; STAHMAN, M. A. A pepsin-pancreatin digest index of protein quality evaluation. Journal of Nutrition, v. 83, n. 3, p. 257-261, 1964.
[2] ASSOCIATION OF OFFICIAL ANALYTICAL CHEMISTS. Official Methods of analysis, 13. Ed., Washington, D.C., 1980 .

[3] AW, T. L.; SWANSON, B. G. Influence of tannin on Phaseolus.vulgaris protein digestibility and quality. Journal of Food Science, v. 50, n. 1, p. 67-71, 1985.

[4] AYKROID, W. R.; DOUGHTY, I. Legumes in human nutrition. FAO Nutritional, v. 19, p. 1-138, 1964.

[5] BHATTY, R. S. Albumin proteins of eight edible grain legume species: electrophoretic patterns and amino acid composition. Journal of Agricultural and Food Chemistry, v. 30, n. 3, p. 620-22, 1982.

[6] BLAGROVE, R. J.; GILLESPIE, J. M. Isolation, purification and characterization of the seed globulins of Lupinus angustifolius. Journal of Plant Physiology, v. 2, n. 1, p. 12-27, 1975.

[7] BLAGROVE, R. J.; GILlESPIE, J. M. Comparative studies on the proteins from seeds of Lupinus angustifolius L. Australian. Journal of Plant Physiology, v. 5, n. 3, p. 651-63, 1975.

[8] CARBONARO, M. et al. Solubility-digestibility relationship of legume proteins. Journal of Agricultural and Food Chemistry, v. 45, n. 9, p. 3387-3394, 1997.

[9] CARBONARO, M. et al. Perspectives into factors limiting in vivo digestion of legume proteins: Antinutritional compounds or storage proteins? Journal of Agricultural and Food Chemistry, v. 48, n. 3, p. 742-749, 2000.

[10] CERLETTI, P. Lupin seed proteins. In: HUDSON, B. J. F., ed. Developments in food proteins. London: Applied Sciences Publishers, 1982. v. 2, cap. 4, p. 133-71.

[11] CERLLETI, P.; FUMAGALLI, A.; VENTURIN, D. Protein composition of seeds of Lupinus albus. Journal of Food Science, v. 43, n. 6, p. 1409-14, 1978.

[12] CHAKRABORTY, P.; SOSULKI, F.; BOSE, A. Ultracentrifugation of salt-soluble proteins in ten legumes species. Journal of the Science of Food and Agriculture, v. 30, n. 8, p. 766-71, 1979.

[13] CHANGO, A. et al. Fractionation by thermal coagulation of lupin proteins: physicochemical characteristics. Food Research International, v. 28, n. 1, p. 91-99, 1995.

[14] COELHO, R. G.; SGARBIERI, V. C. Nutritional evaluation of bean (Phaseolus vulgaris) protein. In vivo versus in vitro procedures. Journal of Food Biochemistry, v. 18, p. 297-309, 1995.

[15] CUADRADO, C. et al. Nutritional utilization by the rat of diets based on lentil (Lens culinaris) seed meal or its fractions. Journal of Agricultural and Food Chemistry, v. 50, n. 15, p. 4371-4376, 2002.

[16] DERBYSHIRE, E.; WRIGHT, D. J.; BOULTER, D. Legumin and vicilin storage proteins of legume seeds. Phytochemistry, v. 15, n. 1, p. 3-24, 1976.

[17] DESHPANDE, S. S.; NIELSEN, S. S. Nitrogenous constituents of selected grain legumes. Journal of Food Science, v. 52, n. 5, p. 1321-5, 1987.

[18] DURANTI, M. et al. The seed globulins of Lupinus albus. Phytochemistry, v. 20, n. 8, p. 2071-2075, 1981.

[19] DURIGAN, J. F.; SGARBIERI, V. C.; BULISANI, E. A. Protein value of dry bean cultivars: factors interfering 
with biological utilization. Journal of Agricultural and Food Chemistry, v. 35, n. 5, p. 694-698, 1987.

[20] EVANS, E.; WITTY, R. An assessment of methods used to vitamin and protein quality. World Review of Nutrition and Dietetic, v. 32, p. 1-26, 1978.

[21] FIELDS, R. The rapid determination of amino groups with TNBS. Methods in Enzymology, v. 25, p. 464-8, 1972.

[22] FRIEDMAN, M. Nutritional value of proteins from different food sources: A Review. Journal of Agricultural and Food Chemistry, v. 44, n. 1, p. 6-29, 1996.

[23] GENOVESE, M. I.; LAJOLO, F. M. Effect of bean (Phaseolus vulgaris) albumins on phaseolin in vitro digestibility, role of trypsin inhibitors. Journal of Food Biochemistry, v. 20, p. 275-94, 1996.

[24] GROSS, R.; BAER, E. V. Posibilidades del Lupinus mutabilis y Lupinus albus en los paises andinos. Archivos Latinoamericanos de Nutricion, v. 27, n. 3 , p. 451-458, 1975

[25] KHAN, M. A.; JACOBSEN I.; EGGUM, B. O. Nutritive value of some improved varieties of legumes. Journal of the Science of Food and Agriculture, v. 30, n. 4, p. 395-400, 1979.

[26] LAEMLLI, U. K. Cleavage of structural proteins during assembly of the head of bacteriophage T-4. Nature, v. 227, n. 5259 , p. $680-85,1970$.

[27] LOWRY, O. H. et al. Protein measurement with the folin phenol reagent. Journal of Biological Chemistry, v. 193, n. 1, p. 265-75, 1951.

[28] MARLETTA, L.; CARBONARO, M.; CARNOVALE, E. In vitro protein and sulphur amino acid availability as a measure of bean protein quality. Journal of the Science of Food and Agriculture, v. 59, n. 4, p. 497-504, 1992 .

[29] MARQUEZ, U. M. L.; LAJOLO, F. M. Composition and digestibility of albumin, globulins, and glutelins from Phaseolus vulgaris. Journal of Agricultural and Food Chemistry, v. 29, n. 5, p. 1068-74, 1981.

[30] McDONOUGH, F. E., et al. In vivo rat assay for true protein digestibility: collaborative study. Journal of the Association of Official and Analytical Chemistry, v. 73, n. 4, p. 801-805, 1990.

[31] MELO, T. S.; FERREIRA, R. B.; TEIXEIRA, A. N. The seed storage proteins from Lupinus albus. Phytochemistry, v. 37, n. 3, p. 641-8, 1994.

[32] NEVES, V. A. Isolation and in vitro hydrolysis of globulin G-1 from lentil (Lens culinaris, Medik). Journal of Food Biochemistry, v. 19, p. 109-120, 1995.

[33] NEVES, V. A.; LOURENÇO, E. J.; SILVA, M. A. Extração, isolamento e fracionamento da proteína de tremoço (Lupinus albus L.), var. Multolupa. Alimentos e Nutrição, v. 12, p. 115-130, 2001.

[34] OOMAH, B. D.; BUSHUK, W. Characterization of lupin proteins. Journal of Food Science, v. 48, n. 1, p. 38-41, 1983.

[35] PELLET, P. L.; YOUNG, V. R. Nutritional evolution of protein foods. The United Nations University, N. Y., 1980. $138 \mathrm{p}$.

[36] REEVES, P. G.; FORREST, H. N.; GEORGE, C. F. AIN93 Purified diets for laboratory rodents: Final report of the American Institute of Nutrition ad hoc writing committee on the reformulation of the AIN-76 ${ }^{\mathrm{A}}$ rodent diet. Journal of Nutrition, v. 123, n. 9, p. 1939-1951, 1993.

[37] ROMERO, J.; RYAN, D. S. Susceptibility of the major storage protein of bean (Phaseolus vulgaris L.) to in vitro enzymatic hydrolysis. Journal of Agricultural and Food Chemistry, v. 26, n. 4, p. 784-88, 1978.

[38] RUBIO, L. A., et al. High in vivo (rat) digestibility of faba bean (Vicia faba), lupin (Lupinus angustifolius) and soya bean (Glycine max) soluble globulins. Journal of the Science of Food and Agriculture, v. 66, n. 3, p. 289-92, 1994.

[39] RUBIO, L. A. et al. The utilization of lupin (Lupinus angustifolius) and faba bean globulins by rats is poorer than of soybean globulins or lactalbumin but the nutritional value of lupin seed meal is lower only than that of lactalbumin. Journal of Nutrition, v. 125, n. 11 , p. 2145-55, 1995.

[40] RUBIO, L. A., et al. Nutrition utilization by rats of chickpea (Cicer arietinum L.) meal and its isolated globulin proteins is poorer than that of deffated soybean or lactalbumin. Journal of Nutrition, v. 128 , n. 6 , p. 1042-47, 1998.

[41] RUBIO, L. A. et al. Organ relative weight and plasma amino acid concentrations in rats fed diets based in whole legume (faba bean, lupin, chickpea, soybean) seed meals or their fractions. Journal of the Science of Food and Agriculture, v. 79, n. 2, p. 187-194, 1999.

[42] RUBIO, L. A.; SEIQUER, I. Transport of aminoacids from in vitro digested legume proteins or casein in Caco-2 cell cultures. Journal of Agricultural and Food Chemistry, v. 50, n. 18, p. 5202-5206, 2002.

[43] SATHE, S. K.; SALUNKHE, D. K. Solubilization and electrophoretic characterization of the great northern bean (Phaseolus vulgaris L.) proteins. Journal of Food Science, v. 46, n. 1, p. 82-87, 1981.

[44] SATHE, S. K.; DESHPANDE, S. S.; SALUNKHE, D. K. Functional properties of lupin seed (Lupinus mutabilis) proteins and protein concentrate. Journal of Food Science, v. 47, n. 3, p. 491-97, 1982.

[45] SGARBIERI, V. C.; GALEAZZI, M. A. M. Some physicochemical and nutritional properties of sweet lupin (Lupinus albus, var. Multolupa) proteins. Journal of Agricultural and Food Chemistry, v. 26, n. 6, p. 1438-42, 1978.

[46] SGARBIERI, V. C. Estudo de conteúdo e de algumas características das proteínas em sementes de plantas da família leguminoseae. Ciência e Cultura, v. 32, p. $78-84,1980$.

[47] SGARBIERI, V. C.; WHITAKER, J. R. Physical, chemical, and nutritional properties of common bean (Phaseolus). Advances in Food Research, v. 28, p. 93-166, 1982.

[48] SINGH, U.; SINGH, B. Tropical grain legumes as important human foods. Economy Botany, v. 46, p. 310-21, 1992.

[49] SPADARO, A. C. C. et al. convenient manual trinitrobenzenesulfonic acid method for monitoring amino acids and peptides in chromatographic column effluents. Analytical Biochemistry, v. 96, n. 2, p. 317-21, 1979. 
[50] TAVANO, O. Avaliação Nutricional de frações protéicas do grão-de-bico (Cicer arietinum L.) var. IAC Marrocos - Estudo in vitro e in vivo. Araraquara, 2002, 94 f. Dissertação (Mestrado em Ciência de Alimentos) - Faculdade de Ciências Farmacêuticas - UNESP, Araraquara, 2002.

[51] WHITAKER, J. R. Determination of molecular weights of proteins by gel filtration on sephadex. Analytical Chemistry, v. 35, n. 12, p. 1950-3, 1963.

\section{6 - AGRADECIMENTOS}

Os autores agradecem à EMBRAPA, Estação Experimental de Passo Fundo, RS, pelas sementes de tremoço, variedade Multolupa e ao Programa de Auxílio ao Desenvolvimento Científico (PADC) da Faculdade de Ciências Farmacêuticas - UNESP - pelo suporte financeiro. 